\title{
ANALYSIS OF STRATEGIC INTERACTIONS \\ IN THE ARMENIA-AZERBAIJAN NAGORNO-KARABAKH CONFLICT THROUGH THE PRISM OF THE GAME THEORY
}

\author{
Jel'shan N. Medzhidov \\ Azerbaijan University of Languages, Baku, Azerbaijan Republic
}

\begin{abstract}
Introduction. The paper attempts to analyze possible and probable strategic moves of the primary and secondary actors in the Armenia-Azerbaijan Nagorno-Karabakh conflict. Methods. To analyze this conflict the author uses the mathematical theory of games and some mathematical models and methods. The main methods and models include the following: Nash equilibrium, sequential game, Zermelos theorem, Zermelo-Kuno algorithm, and games with commitments. As the publication is an analytical and computational work, it mainly includes literature related to methodology and theory. Analysis. The publication not only contains the analysis of the strategic interactions between Armenia and Azerbaijan as primary actors, but also includes Russia as a secondary participant. Results. As a result, the author has drawn several conclusions. Firstly, the strategic interactions between two actors differ from strategic interactions among three actors in terms of possible payments and preferences. Secondly, in the strategic interactions between Armenia and Azerbaijan, the most likely interaction profile will be " $\mathrm{A}_{2}, \mathrm{~B}_{1}-\mathrm{C}_{2}$ " (not recognizing the independence of Nagorno Karabakh and not declaring war on Armenia) with a payment of " $0: 0$ ". The third conclusion is on the qualitative difference between the sequential game and the game with commitments among Armenia, Azerbaijan and Russia. In the second case, the Nash equilibrium consists of not recognizing the separatist regime by Armenia, not supporting Russia's desire for Armenia to recognize and not declaring war on Armenia: $S P N E=\left\{E_{2}, R_{4}, \mathrm{~A}_{8}\right\}$. However, unlike the first option, the equilibrium obtained in the game with commitments takes on a more stable structure in relation to different political processes.

Key words: Nagorno-Karabakh conflict, Azerbaijan, Armenia, Russia, game theory, Nash equilibrium, strategic interactions, payments.

Citation. Medzhidov J.N. Analysis of Strategic Interactions in the Armenia-Azerbaijan Nagorno-Karabakh Conflict Through the Prism of the Game Theory. Vestnik Volgogradskogo gosudarstvennogo universiteta. Seriya 4. Istoriya. Regionovedenie. Mezhdunarodnye otnosheniya [Science Journal of Volgograd State University. History. Area Studies. International Relations], 2020, vol. 25, no. 3, pp. 140-147. (in Russian). DOI: https://doi.org/10.15688/ jvolsu4.2020.3.12
\end{abstract}

\section{АНАЛИЗ СТРАТЕГИЧЕСКИХ ВЗАИМОДЕЙСТВИЙ В АРМЯНО-АЗЕРБАЙДЖАНСКОМ НАГОРНО-КАРАБАХСКОМ КОНФЛИКТЕ ЧЕРЕЗ ПРИЗМУ ТЕОРИИ ИГР}

\author{
Эльшан Назимович Меджидов \\ Азербайджанский университет языков, г. Баку, Азербайджанская Республика
}

Аннотация. Введение. В статье предпринята попытка проанализировать возможные и вероятные стра-
тегические ходы первостепенных и некоторых второстепенных акторов в Армяно-Азербайджанском Нагор-
но-Карабахском конфликте. Mетоды. В исследовании данного конфликта применяется математическая тео-
рия игр и вытекающие из нее некоторые математические модели и методы. В качестве основных методов и
моделей, использованных в данной публикации, можно перечислить: равновесие Нэша, игры в развернутой
форме, теорему Цермело, алгоритм Цермело - Куно, а также игры с коммитментом. Поскольку публикация 
является аналитической и вычислительной работой, то она в основном включает в себя литературу, связанную с методологией и теорией. Анализ. Статья не только содержит анализ стратегических взаимодействий Армении и Азербайджана в качестве первостепенных акторов конфликта, но и включает Россию в качестве второстепенного участника регулирования конфликта. Результаты. В результате проведенных расчетов было сделано несколько выводов. Во-первых, было выяснено, что стратегические взаимодействия между двумя акторами отличаются от стратегических взаимодействий между тремя акторами по возможным платежам и по предпочтениям каждого из сторон. Во-вторых, в стратегических взаимодействиях между Арменией и Азербайджаном наивероятнейший профиль взаимодействия будет « $\mathrm{A}_{2}, \mathrm{~B}_{1}-\mathrm{C}_{2}$ » (непризнания независимости НК и необъявления войны Армении) с платежом «0:0». Третий вывод касается качественного отличия между простой развернутой игрой и игрой с коммитментом между Арменией, Азербайджаном и Россией. Во втором случае равновесие Нэша, совершенное на подыграх, снова состоит из непризнания сепаратистского режима Арменией, неподдержки Россией желания Армении о признании и необъявления войны Армении Азербайджаном: $S P N E=\left\{E_{2}, R_{4}, \mathrm{~A}_{8}\right\}$. Однако в отличие от первого варианта равновесие, полученное в игре с коммитментом, приобретает более устойчивую структуру по отношению к разным политическим процессам.

Ключевые слова: Нагорно-Карабахский конфликт, Азербайджан, Армения, Россия, теория игр, равновесие Нэша, стратегические взаимодействия, платежи.

Цитирование. Меджидов Э. Н. Анализ стратегических взаимодействий в Армяно-Азербайджанском Нагорно-Карабахском конфликте через призму теории игр // Вестник Волгоградского государственного университета. Серия 4, История. Регионоведение. Международные отношения. - 2020. - Т. 25, № 3. - С. 140-147. DOI: https://doi.org/10.15688/jvolsu4.2020.3.12

Введение. Кавказ является важным геополитическим и геоэкономическим регионом. Он является своеобразной артерией, связывающей восток с западом, север с югом, Азию с Европой и Россию с Ираном. Однако региональные политические конфликты, территориальные споры и военные столкновения увеличивают нестабильность региона, угрожая безопасности и интересам многих игроков. Видный ученый Кеннет Оу начинает свой научный труд «Условия для сотрудничества в мировой политике» тезисом о том, что государства не испытывают принуждения для выполнения данного ими обязательства при отсутствии надгосударственного центрального органа в международных отношениях. Исходя из этого тезиса ученый делает логическое умозаключение и предлагает рассматривать продолжительность и перспективы сотрудничества через призму совпадающих друг с другом интересов государств [5, р. 69-70].

Великий древнекитайский военный мыслитель Сунь Цзы изрек: «Кто - еще до сражения - побеждает предварительным расчетом, у того шансов много; кто - еще до сражения - не побеждает расчетом, у того шансов мало. У кого шансов много - побеждает; у кого шансов мало - не побеждает; тем более же тот, у кого шансов нет вовсе. Поэтому для меня - при виде этого одного - уже ясны победа и поражение» [3, с. 26].

Методы. Анализ политических позиций, государственных интересов, стратегических «платежей» и возможных ходов сторон в Армяно-Азербайджанском Нагорно-Карабахском конфликте создают основу для применения методов теории игр к этому международному конфликту. Теория игр - это область науки, которая исследует стратегические решения правительств, фирм и индивидуумов. Стратегическое решение - это решение, которое принимает в расчет ходы других игроков и влияет на полезность других агентов. Игра - это любое стратегическое взаимодействие нескольких агентов, а игроки - участники этого взаимодействия [2, с. 3-4]. Для того чтобы успешно применить теорию игр к Армяно-Азербайджанскому Нагорно-Карабахскому конфликту, необходимо придерживаться нескольких важных постулатов:

- указать множество игроков;

- указать множество возможных стратегий каждого игрока;

- указать платеж, который получает каждый игрок.

Стоит особо упомянуть, что теория игр предполагает упрощение любого исследуемого вопроса и требует отбрасывать все неприоритетные детали. Именно поэтому в данной 
статье не рассматриваются все возможные детали конфликта, а дается целенаправленный анализ приоритетных сторон стратегических взаимодействий акторов. Согласно теории игр, игры подразделяются на одновременные игры и последовательные игры. Можно успешно применить одновременные игры к НагорноКарабахскому конфликту, однако в этой статье мы в качестве метода выбрали модели последовательных игр [2, с. 56-71]. В качестве основных моделей здесь выступают равновесие Нэша, игры в развернутой форме, теорема Цермело, алгоритм Цермело - Куно, игры с коммитментом.

Анализ. Шансы эскалации АрмяноАзербайджанского Нагорно-Карабахского конфликта до уровня новой полномасштабной войны могут быть смоделированы и решены в форме последовательных игр. Общеизвестно, что признание самопровозглашенного образования Нагорного Карабаха является важной стратегической дилеммой для Армянской Республики. После любого решения Армении (признать или не признать), Азербайджан предстанет перед дилеммой о начале войны с Арменией (объявлять войну или не объявлять). В форме развернуто-последовательной игры условные платежи Азербайджана можно систематизировать следующим образом:

- с одной стороны, Азербайджан не желает признания Арменией сепаратистского образования в качестве независимого государства, а с другой стороны, не желает встречаться с тяготами новой войны [1];

- наилучший вариант для Азербайджана - непризнание Арменией независимости самопровозглашенного образования и необъявление Азербайджаном войны Армении;

- в случае признания Арменией самопровозглашенного образования, объявление или необъявление войны Армении имеет одинаковый негативный результат;

- объявление войны Армении в случае непризнания самопровозглашенного образования лучше, чем объявление войны в случае признания самопровозглашенного образования (так как во втором случае Азербайджан сталкивается как с тяготами войны, так и с фактом признания независимости);

- наихудший вариант для Азербайджана - необъявление войны Армении в случае признания независимости сепаратистского режима.

Платежи Республики Армении, в свою очередь, включают в себя следующие пункты:

- самый оптимальный вариант - признание независимости в условиях необъявления войны Азербайджаном;

- война с Азербайджаном хуже признания независимости Нагорного Карабаха (НК);

- в случае неизбежности войны признание независимости НК лучше непризнания;

- наихудший вариант - война с Азербайджаном при условии непризнания независимости Нагорного Карабаха.

Схема последовательной игры вместе с поочередным принятием акторами решений, а также их возможные варианты и условные платежи изображены на рисунке 1.

В составленной в развернутой форме игре вершины, указывающие платежи, называются терминалами, а нетерминальные вершины называются подыгрой. На рисунке 1 имеется подыгра трех нетерминальных вершин: «А», «В» и «С». У Армении есть две такие стратегии как «признавать независимость» $\left(\mathrm{A}_{1}\right)$ и «не признавать независимость» $\left(\mathrm{A}_{2}\right)$ сепаратистского образования. У Азербайджана же есть 4 возможные стратегии: объявить войну в любой случае $\left(\mathrm{B}_{1}, \mathrm{C}_{1}\right)$, объя-

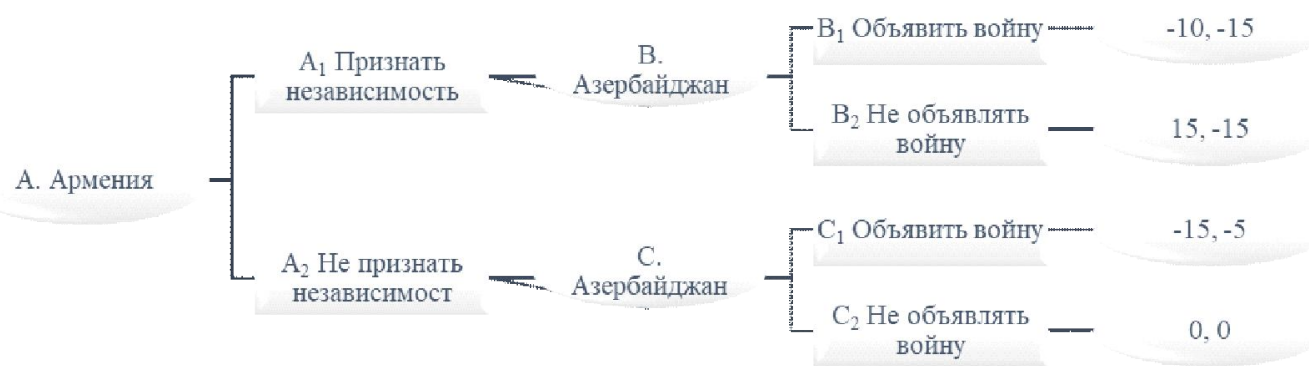

Рис. 1

Fig. 1 
вить войну в случае признания и не объявлять войну в случае непризнания $\left(\mathrm{B}_{1}, \mathrm{C}_{2}\right)$, объявить войну в случае непризнания и не объявить войну в случае признания независимости $\left(\mathrm{C}_{1}, \mathrm{~B}_{2}\right)$, не объявлять войну ни при каких обстоятельствах $\left(\mathrm{B}_{2}, \mathrm{C}_{2}\right)$.

Дальнейшим необходимым шагом является составление в виде матрицы (см. таблицу) профилей наилучших ответов Азербайджана и Армении. В составленной матрице наилучший ответ Азербайджана на решение Армении обозначен штрихом, а наилучший ответ Армении на решение Азербайджана обозначен символом звезды.

Как видим, в полученной матрице есть 3 разных равновесия Нэша: объявление войны Азербайджаном Армении при непризнании Арменией сепаратистского режима $\left(\mathrm{A}_{2}, \mathrm{~B}_{1}-\mathrm{C}_{2}\right)$, объявление Азербайджаном войны Армении при условии признания Арменией сепаратистского режима $\left(\mathrm{A}_{1}, \mathrm{C}_{1}-\mathrm{B}_{2}\right)$ и объявление Азербайджаном войны Армении в любом случае $\left(\mathrm{A}_{1}, \mathrm{~B}_{2}-\mathrm{C}_{2}\right)$.

Итак, на первый взгляд проведенные расчеты не объясняют причины непризнания Арменией Нагорного Карабаха и ненаступления начала новой войны. Наоборот, полученная матрица, исходя из профилей « $\mathrm{A}_{1}, \mathrm{C}_{1}-\mathrm{B}_{2}$ » и « $\mathrm{A}_{1}, \mathrm{~B}_{2}-\mathrm{C}_{2}$ », выявляет интерес Армении к признанию независимости НК.

Для решения данной задачи целесообразно обратиться к алгоритму Цермело - Куно и решить задачу от конца к его началу [7, p. 4]. Среди существующих профилей Азербайджана стратегия $\mathrm{C}_{2}$ (не объявление войны в случае непризнания независимости), будучи самой прибыльной, обусловливает принятие этой стратегии. Определив с помощью расчетов наивероятнейший ход Азербайджана, Армения для максимизации своего платежа выберет стратегию признания независимости Нагорного Карабаха $\left(\mathrm{A}_{1}\right)$. Таким образом, профили « $\mathrm{A}_{1}, \mathrm{C}_{1}-\mathrm{B}_{2}$ » и « $\mathrm{A}_{1}, \mathrm{~B}_{2}-\mathrm{C}_{2} »-$ это равновесия Нэша, совершенные на подыгре (SPNE) [6, p. 101-103].

Однако причиной, по которой Армения до сих пор не признала независимость Нагорно- го Карабаха, является коллизия между политической теорией и практикой. Для решения этой коллизии надо еще раз взглянуть на матрицу платежей и обратить внимание на то, что к стратегии « $\mathrm{A}_{1}$ » Армении у Азербайджана в двух стратегиях имеется равнозначный платеж. Из-за того, что объявление и необъявление войны при условии признания независимости имеет одинаковый платеж (-15 и -15), то имеется $1 / 2$ вероятности объявления Азербайджаном войны Армении. А это, в свою очередь, в наихудшем случае несет риск снижения платежей Армении в профилях « $\mathrm{A}_{1}, \mathrm{C}_{1}-\mathrm{B}_{2}$ » и « $\mathrm{A}_{1}, \mathrm{~B}_{2}-\mathrm{C}_{2}$ » сразу на 25 пунктов. Таким образом, оказавшись перед риском войны с Азербайджаном, Армения предстает перед трилеммой следующих платежей: «-15», «-10» və «0». Это обусловливает принятие стратегического решения для получения самого прибыльного профиля « $\mathrm{A}_{2}, \mathrm{~B}_{1}-\mathrm{C}_{2} »$ с платежом «0».

Стоит особо подчеркнуть, что привлечение в развернутую игру Армении и Азербайджана дополнительных игроков приводит к изменению в постулатах и платежах игры. Если к игре подключить Россию в качестве третьего игрока, то постулаты и последовательность игры изменится. В начале Армения принимает решение о признании или непризнании Нагорного Карабаха. После Армении стратегический союзник первого и стратегический партнер Азербайджана - Россия - принимает решение о поддержке или отказе поддерживать решение Армении. После этого Азербайджан, исходя из решения первых двух игроков, решает объявлять или не объявлять войну Армении.

Множество возможных стратегий Армении состоит из признания или непризнания независимости НК: $E=\left\{E_{1}, E_{2}\right\}$. Возможные стратегии России - это при любых условиях поддержать Армению $\left(R_{1}, R_{3}\right)$, поддержать Армению в случае признания независимости и не поддерживать в случае непризнания $\left(R_{1}, R_{4}\right)$, поддержать Армению в случае непризнания независимости и не поддерживать в случае признания $\left(R_{3}, R_{2}\right)$, не поддерживать при лю-

\begin{tabular}{|c|l|l|l|l|l|}
\hline & \multicolumn{5}{|c|}{ Азербайджан } \\
\hline \multirow{4}{*}{ Армения } & & $\mathrm{B}_{1}-\mathrm{C}_{1}$ & $\mathrm{~B}_{1}-\mathrm{C}_{2}$ & $\mathrm{C}_{1}-\mathrm{B}_{2}$ & $\mathrm{~B}_{2}-\mathrm{C}_{2}$ \\
\cline { 2 - 6 } & $\mathrm{A}_{1}$ & $-10,-15^{\prime}$ & $-10,-15^{\prime}$ & $* \mathbf{1 5}, \mathbf{- 1 5}$ & $* \mathbf{1 5}, \mathbf{- 1 5 ^ { \prime }}$ \\
\cline { 2 - 6 } & $\mathrm{A}_{2}$ & $-15,-5$ & $* \mathbf{0 , \mathbf { 0 } ^ { \prime }}$ & $* 15,-15$ & $0,0^{\prime}$ \\
\hline
\end{tabular}


бых условиях $\left(R_{2}, R_{4}\right)$. У Азербайджана при такой развернутой игре есть такие возможные стратегии, как: объявить войну при любых условиях ( $\left.\mathrm{A}_{1}, \mathrm{~A}_{3}, \mathrm{~A}_{5}, \mathrm{~A}_{7}\right)$, объявить войну в случае «признания-поддержки» и не объявлять войну в случае комбинации «признания и неподдержки» $\left(\mathrm{A}_{1}, \mathrm{~A}_{4}\right)$, не объявлять войну в случае «признании-поддержки» и объявить войну в случае «непризнания-поддержки» $\left(\mathrm{A}_{2}, \mathrm{~A}_{5}\right)$, объявить войну при комбинации «признания и неподдержки» и не объявить войну в случае «непризнания-поддержки» $\left(\mathrm{A}_{3}, \mathrm{~A}_{6}\right)$, не объявить войну при комбинации «признания и неподдержки» и объявить войну в случае «непризнания-поддержки» $\left(\mathrm{A}_{4}, \mathrm{~A}_{7}\right)$, объявить войну в случае «непризнания-поддержки» и не объявить войну при комбинации «непризнания и неподдержки» $\left(\mathrm{A}_{5}, \mathrm{~A}_{8}\right)$, не объявлять войну при любых условиях $\left(\mathrm{A}_{2}, \mathrm{~A}_{4}, \mathrm{~A}_{6}, \mathrm{~A}_{8}\right)$.

Согласно новым постулатам изменившиеся платежи Армении принимают такую форму, что для Армении самым оптимальным вариантом является признание сепаратистского режима при поддержке России и необъявление войны Азербайджаном. Война с Азербайджаном из-за признания при поддержке решения Россией является наилучшим вариантом, нежели непризнание На- горного Карабаха при тех же условиях. Наихудший вариант для Армении - при непризнании Нагорного Карабаха и неподдержке России оказаться в состоянии войны с Азербайджаном. При всем этом, в случае неизбежности войны и в случае неподдержки России, признание сепаратистского режима более предпочтительно, нежели предыдущий вариант.

Платежи России можно условно сгруппировать таким образом, что для России оптимальным вариантом является неподдержка Армении, непризнание Арменией сепаратистского режима и неначало новой войны на Кавказе. При неизбежности войны и признания НК поддержка Армении является более перспективной, чем неподдержка Армении. Для России приоритетнее неначало новой войны на Кавказе, нежели поддержка Армении в признании НК. При этом поддержать Армению при условиях непризнания независимости НК хуже, чем не поддерживать. Наихудший вариант для России - решение Армении о признании, новая война на Кавказе и неподдержка Армении Россией.

Оптимальный вариант для Азербайджана - неподдержка Россией Армении, непризнание НК Арменией и необращение Азербай-

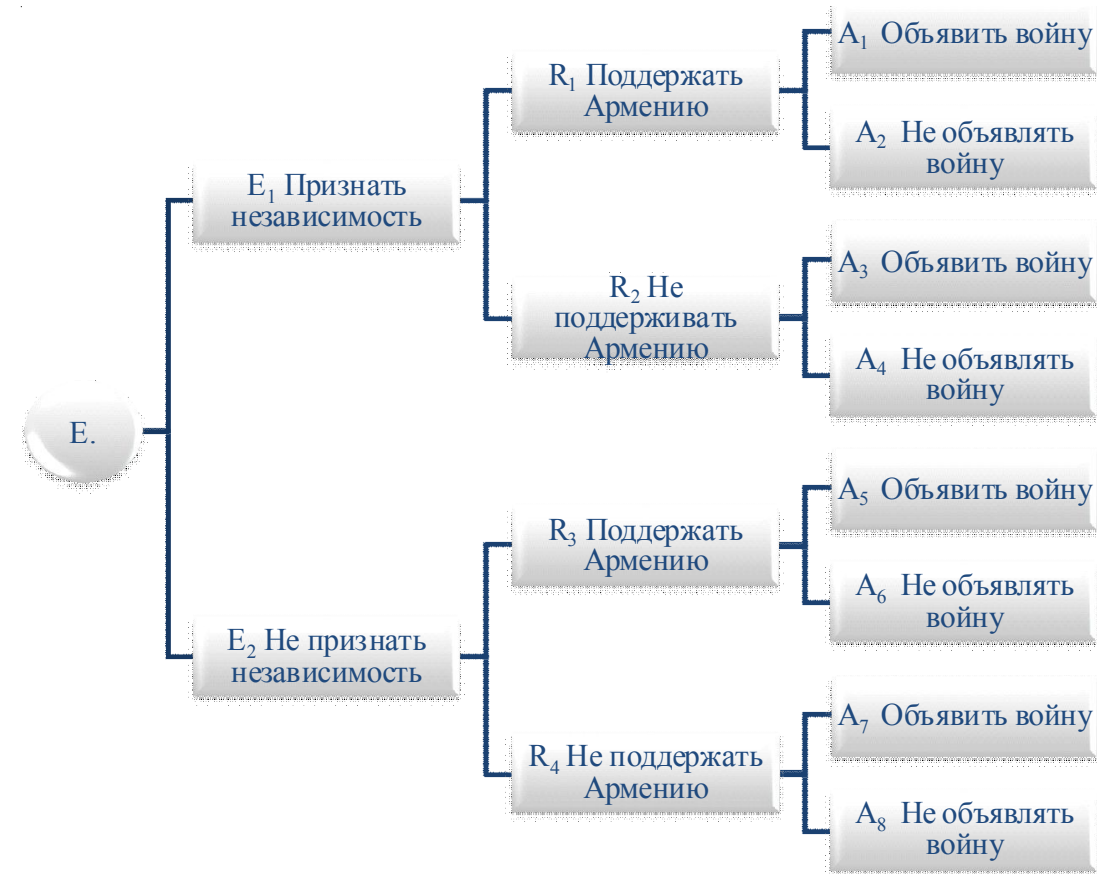

Рис. 2

Fig. 2 
джана к полномасштабной войне. При условии неподдержки России, но признания Арменией независимости НК, объявление или необъявление войны Армении одинаково плохо для Азербайджана. Наихудшим вариантом для Азербайджана является объявление войны Армении при условиях поддержки и признания.

Обращаясь к алгоритму Цермело - Куно, мы можем определить, что Азербайджан выберет стратегию $\mathrm{A}_{8}$. Из всех возможных стратегий России самым прибыльным является неподдержка Армении при условии непризнания НК Арменией $\left(R_{4}\right)$. Для Армении оптимальный вариант - признание независимости при условии поддержки этого решения Россией и необъявления войны Азербайджаном $\left(E_{1}\right)$.

Однако Армения понимает, что в случае принятия в одностороннем порядке стратегии $E_{1}$ для предотвращения войны на Кавказе и для того, чтобы не потерять стратегическое партнерство с Азербайджаном, Россия его не поддержит, Армения столкнется с $1 / 2$ вероятностью новой войны с Азербайджаном. При таком раскладе Армения изменит стратегию и выберет стратегию $E_{2}$ о непризнании НК. Таким образом, равновесие Нэша, совершенное на подыграх, состоит из непризнания Арменией сепаратистского образования, неподдержки Россией Армении в желании признать НК и необъявления Азербайджаном войны Армении: $S P N E=\left\{E_{2}, R_{4}, \mathrm{~A}_{8}\right\}$.

Проведенные расчеты объясняют позиции трех государств в трехсторонних встречах о статусе региона. Несмотря на то что факт (при условии «признания и неподдержки» для Азербайджана) объявления и необъявления войны имеет одинаковый негативный выигрыш, вся эта ситуация создает нестабильность и дает возможность к многосторонним манипуляциям. Это может дать определенные стимулы России поддержать решение Армении признать сепаратистский режим в случае серьезных геополитических и геоэкономических проблем с Азербайджаном. При таком раскладе в новой войне наибольший вред получил бы Азербайджан. Поэтому маловероятно, что Азербайджан выберет стратегию объявления войны.

Однако у Азербайджана все же есть возможность улучшить свою позицию и добить- ся стабильного равновесия Нэша, совершенного на подыграх. Для этого надо трансформировать развернутую игру в игру с коммитментом и целенаправленно сократить количество доступных стратегий [4, p. 11]. Одна из таких возможностей - это через референдум возложить на главнокомандующего вооруженными силами Азербайджана обязанность объявить войну Армении в случае признания сепаратистского режима несмотря ни на какие факторы. В такой развернутой игре с коммитментом Азербайджан добровольно лишает себя таких стратегий, как необъявление войны в случае признания-поддержки $\left(\mathrm{A}_{2}\right)$ и признания и неподдержки $\left(\mathrm{A}_{4}\right)$. При таком положении дел схема развернутой игры с коммитментом приобретает форму, изображенную на рисунке 3.

При таком раскладе Россия, для которой предотвращение новой войны на Кавказе приоритетнее поддержки Армении и давления на Азербайджан, никогда не выберет стратегию « $R_{1} »$, что, в свою очередь, сдержит Армению от принятия стратегии « $E_{2} »$.

Результаты. Согласно теореме Цермело в любой конечной последовательной игре с полной информацией существует равновесие Нэша, совершенное на подыграх. Итак, равновесие Нэша, совершенное на подыграх, снова состоит из непризнания сепаратистского режима Арменией, неподдержки Россией желания Армении о признании и необъявлении войны Армении Азербайджаном: $S P N E=\left\{E_{2}, R_{4}, \mathrm{~A}_{8}\right\}$. Однако, в отличие от первого варианта, равновесие, полученное в игре с коммитментом, приобретает более устойчивую структуру по отношению к разным политическим процессам.

Один из главных факторов, предотвращающих возобновление новой крупномасштабной войны в Закавказье, - это неопределенность, связанная с позицией третьей стороны. Азербайджан, который превосходит Армению в категориях силы и мощи, все равно перед началом боевых действий обязан рассчитать возможные ходы и вероятность этих возможных ходов стратегического союзника Армении - России. Заметим, что анализ и математические расчеты необходимы не только по отношению к возможным действиям России, но и к возможным действиям Турции, 


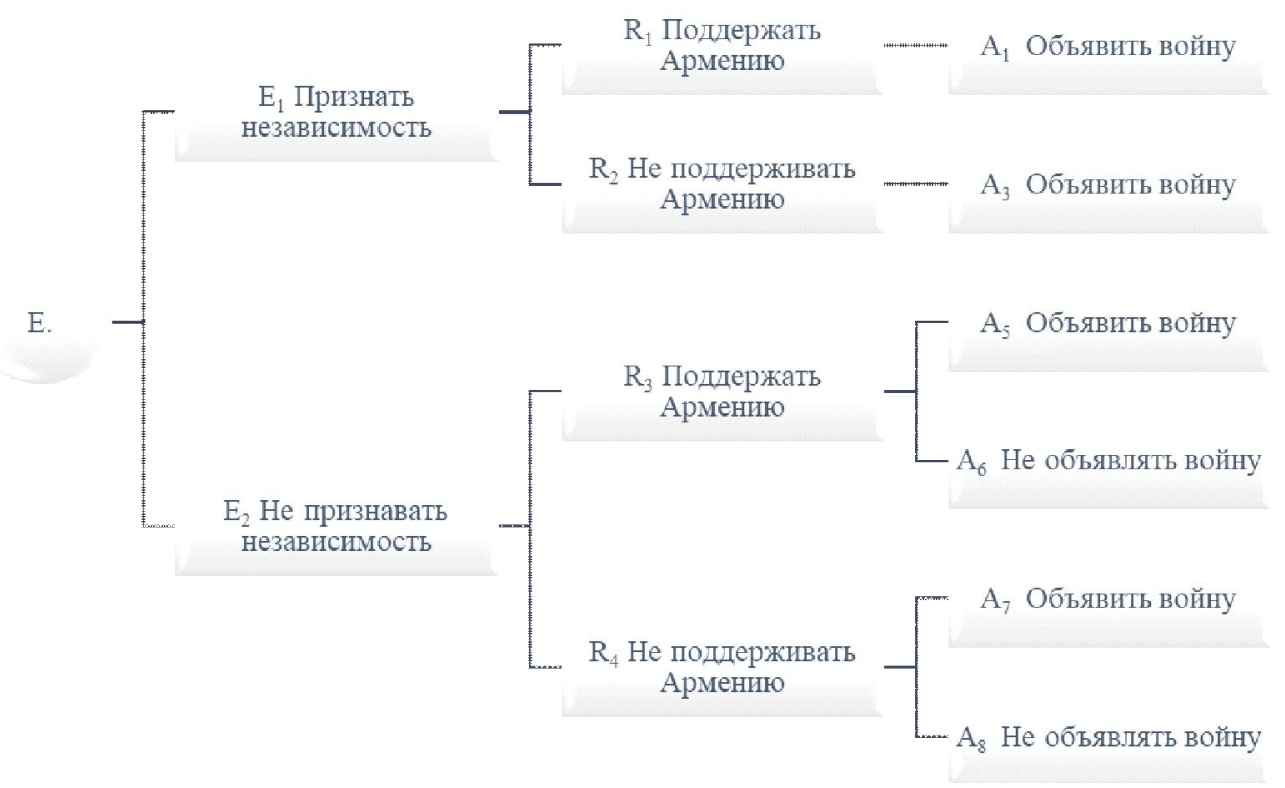

Рис. 3

Fig. 3

Ирана, США и ЕС. Только лишь при правильном расчете позиций всех сторон силовое решение Армяно-Азербайджанского НагорноКарабахского конфликта может стать темой обсуждения.

\section{СПИСОК ЛИТЕРАТУРЫ}

1. В рамках Мюнхенской конференции по безопасности состоялись панельные обсуждения по Армяно-Азербайджанскому Нагорно-Карабахскому конфликту, 15 февраля 2020, 20:30. - Электрон. текстовые дан. - Режим доступа: https://ru.president. az/articles/35813 (дата обращения: 26.05.2020). - Загл. с экрана.

2. Григорьев, А. В. Теория Игр : учеб. пособие / А. В. Григорьев. - Томск : Изд-во ТГАСУ, 2014. $-79 \mathrm{c}$.

3. Сунь-цзы. Искусство войны / Сунь-цзы. M. : ACT, 2014. $-192 \mathrm{c}$.

4. Itai,A. Commitments in Extensive Form Games / A. Itai, Ya. Babichenko, M. Tennenholtz. - 2015. May 16. - P. 1-31. - Electronic text data. - Mode of access: https://papers.ssrn.com/sol3/papers.cfm? abstract_id=2613019 (date of access: 10.12.2019). Title from screen.

5. Art, J. R. International Politics: enduring concepts and contemporary issues / R. J. Art, R. Jervis. - N. Y. : Pearson Education, 2007. -586 p.

6. Rubinstein, A. Perfect Equilibrium in a Bargaining Model / A. Rubinstein // Econometrica. 1982. - № 50. - P. 97-109.
7. Schwalbe, U. Zermelo and the Early History of Game Theory/ U. Schwalbe, P. Walker. - United States, Massachusetts, Cambridge : Harvard University Press, 1999. $-15 \mathrm{p}$.

\section{REFERENCES}

1. V ramkakh Myunkhenskoy konferentsii po bezopasnosti sostoyalis panelnye obsuzhdeniya po armyano-azerbaydzhanskomu nagorno-karabakhskomu konfliktu, 15 fevralya 2020, 20:30 [Panel Discussions on the ArmenianAzerbaijan Nagorno-Karabakh Conflict Were Held Within the Framework of the Munich Security Conference, February 15, 2020, 20:30.] URL: https:// ru.president. az/articles/35813 (accessed 26 May 2020).

2. Grigoryev A.V. Teoriya Igr: uchebnoe posobie [Game Theory. Study Guide]. Tomsk, Izd-vo TGASU, $2014.79 \mathrm{p}$.

3. Sun Tzu. Iskusstvo voyny [The Art of War]. Moscow, AST Publ., 2014. 192 p.

4. Itai A., Babichenko Ya., Tennenholtz M. Commitments in Extensive Form Games, 2015, May 16, pp. 1-30. URL: https://papers.ssrn.com/sol3/papers. cfm?abstract_id=2613019 (accessed 10 December 2019).

5. Art J.R., Jervis R. International Politics: Enduring Concepts and Contemporary Issues. New York, Pearson Education, 2007. 586 p.

6. Rubinstein A. Perfect Equilibrium in a Bargaining Model. Econometrica, 1982, no. 50, pp.97-109.

7. Schwalbe U., Walker P. Zermelo and the Early History of Game Theory. Cambridge, Harvard University Press, 1999. 15 p. 
Анализ стратегических взаимодействий в Армяно-Азербайджанском Нагорно-Карабахском конфликте

\section{Information About the Author}

Jel'shan N. Medzhidov, Doctoral Student, Lecturer, Azerbaijan University of Languages, Rashida Bekhbutova St., Baku,Azerbaijan Republic, madjidov_elshan@mail.ru, https://orcid.org/0000-0003-1875-8533

\section{Информация об авторе}

Эльшан Назимович Меджидов, докторант, преподаватель, Азербайджанский университет языков, ул. Рашида Бехбутова, г. Баку, Азербайджанская Республика, madjidov_elshan@mail.ru, https://orcid.org/0000-0003-1875-8533 